\title{
Perencanaan Dan Perancangan Stasiun Kereta Api Pada Bandar Udara Ahmad Yani Di Kota Semarang
}

\author{
Rian Mas Nugroho ${ }^{1 *}$, Agus Heru Purnomo ${ }^{2}$, Edi Pramono Singgih ${ }^{3}$ \\ Program Studi Arsitektur, Fakultas Teknik, Universitas Sebelas Maret Surakarta ${ }^{1}$ \\ Email : rianmasnugroho@yahoo.com* \\ Program Studi Arsitektur, Fakultas Teknik, Universitas Sebelas Maret Surakarta ${ }^{2}$ \\ Program Studi Arsitektur, Fakultas Teknik, Universitas Sebelas Maret Surakarta ${ }^{3}$
}

\begin{abstract}
The railway station at Ahmad Yani airport in Semarang is a work of architecture discipline. The goal is to get the design of the airport train station in Semarang. With the railway station at Ahmad Yani Airport Semarang is to facilitate passengers who want to continue their journey, either from plane to train or vice versa. It is also expected that with this railway station can reduce congestion that occurred in Semarang, people outside Semarang who want to pick up his family at the airport do not have to come all the way to Ahmad Yani airport, because passengers domiciled outside the Semarang can Use a train to get to their respective areas. By using the accessibility method, it is expected that this station can facilitate the passengers who want to use rail transportation modes or who want to change the mode of transportation. Of course, the selection of the site has also been through several analyzes. The chosen site is also very precise because it is on the south side of the Ahmad Yani airport and is on the railway line. And also on the east side of the tread is the main road to get to the airport. So, on the highway is access to the station. The shape, layout and location of the station building also prioritizes the accessibility of its users. The facilities provided are also designed to facilitate passengers such as the addition of escalators, travellators, ramps, guiding blocks, bridges, etc. The concept used indirectly can provide convenience and comfortable of the passengers who want to change the mode of transportation.
\end{abstract}

Keywords: railway station, airport station, intermodal transportation integration, accessibility

\section{PENDAHULUAN}

Dewasa ini, moda transportasi kereta api adalah salah satu moda transportasi yang paling digemari oleh masyarakat Indonesia, karena kerta api dianggap lebih murah, nyaman dan cepat. Dari anak kecil hingga orang tua juga senang bepergian menggunakan kereta api, baik itu jarak jauh maupun jarak dekat. Karena kereta api adalah salah satu moda transportasi favorit masyarakat maka tak heran jika akhir-akhir ini pengembangan terus menerus dilakukan demi mewujudkan pelayanan publik yang baik dan nyaman. Dari pengaktifan kembali stasiun yang sudah mati, penambahan rel ganda di pulau jawa, pengembangan di stasiun-stasiun besar hingga mengaktifan kembali jalur-jalur kereta yang sudah mati.

Selain itu, pada saat ini pemerintah sedang merencanakan penggabungan antara beberapa moda transportasi. Seperti yang tertera pada UU nomor 23 tahun 2007 tentang perkeretaapian, "bahwa transportasi mempunyai peranan penting dalam mendukung pertumbuhan ekonomi, pengembangan wilayah dan pemersatu wilayah Negara Kesatuan Republik Indonesia dalam rangka mewujudkan Wawasan Nusantara, serta memperkukuh ketahanan nasional dalam usaha mencapai tujuan nasional berdasarkan Pancasila dan UndangUndang Dasar Negara Republik Indonesia Tahun 1945”.("UU nomor 23 tahun 2007 tentang perkeretaapian,”.

Beberapa stasiun dan bandara di Indonesia telah terintegrasi satu sama lain, seperti bandara sukarno hatta yang ada di Jakarta, bandara kualanamu yang ada di Medan, bandara adi sucipto yang ada di Yogyakarta, dll. kemudian rencananya pemerintah akan terus menggerakan penggabungan antara stasiun dan bandara di seluruh bandara yang ada di Indonesia termasuk juga bandara ahmad yani Semarang. 
Bandara ahmad yani Semarang tergolong mudah untuk di integrasikan dengan stasiun kereta api. Karena pada bagian selatan bandara ahmad yani ini terdapat jalur kereta api aktif dan gerbang masuk bandara terdapat perlintasan kereta api. Maka tidaklah sulit jika harus membangun sebuah stasiun kereta api pada bandara ini.

Perkembanganya saat ini, pemerintah telah melakukan pembebasan lahan yang tadinya milik TNI-AD akan diambil alih oleh pemerintah guna membangun sebuah stasiun kereta api. Rencana tersebut telah ada sejak tahun 2011 namun hingga saat ini belum ada keterangan lebih lanjut perkembangan pembangunan stasiun kereta api bandara ini.

\section{METODE}

Jenis kegiatan, pelaku, penzoningan, peruangan dan besaran ruangan seluruhnya terlah diatur dalam buku pedoman standarisasi stasiun tahun 2012. Dalam buku ini terlah diatur sebagaimana mestinya sebuah stasiun kereta api yang ada di Indonesia.

Stasiun kereta api pada bandara ahmad yani ini menerapkan metode aksesibilitas. Yaitu desain dari bangunan lebih mengutamakan aksesibilitas bagi penggunanya. Memberikan kemudahan sirkulasi bagi penumpang baik yang akan naik ataupun turun dari stasiun serta memberikan fasilitas bagi penumpang yang akan menuju bandara.

Dengan menggunakan metode aksesbilitas, maka hal ini juga akan berdampak pada bentuk bangunan dan ruang, gubahan dan tata massa bangunan serta tampilan bangunan.

\section{HASIL DAN PEMBAHASAN}

Tapak

Dalam penentuan tapak perlu dilakukan pertimbangan, dan dari hasil pertimbangan yang sudah dilakukan, maka tapak yang tepat sebagai stasiun bandara Ahmad Yani adalah pada sebidang tanah yang berada di depan bandara. Dengan luas tapak 2.6 hektar. Yang terletak di sebelah timur jalan bandara Ahmad Yani Semarang dan disebelah selatan bandara Ahmad Yani Semarang. Karena lokasinya sangat dekat dengan pintu masuk utama bandara Ahmad Yani sehingga tapak ini dipilih agar penumpang tidak perlu berjalan jauh untuk berpindah moda transportasi dari stasiun ke bandara ataupun sebaliknya. Luas tapak yaitu 1,4 hektar. Sehingga fasilitas akan lebih lengkap jika stasiun bandara ini memiliki lahan yang luas.

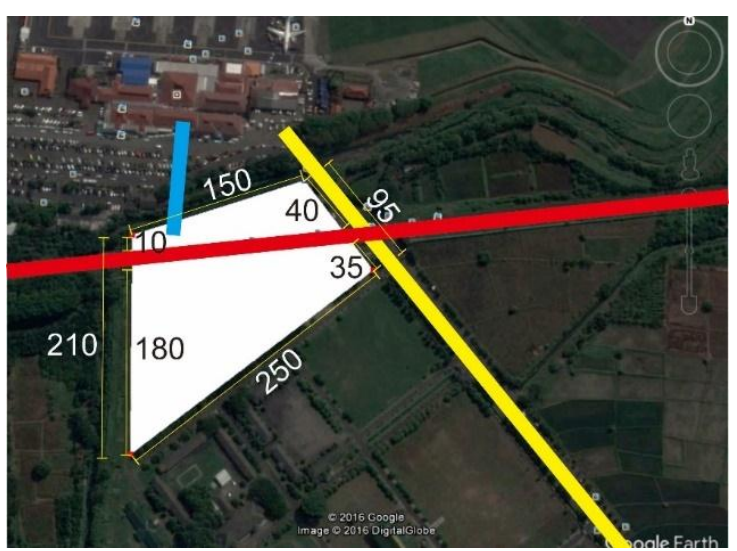

Gambar 1. Ukuran dan posisi tapak

\section{Pencapaian}

Main entrance dan side entrance harus mudah dilihat, mudah diakses dan memiliki sirkulasi yang aman penumpang dapat mengakses bangunan stasiun dengan mudah.

Tujuan : lokasi main entrance dan side entrance pada tapak.

Dasar Pertimbangan :

a. Sirkulasi tapak tidak menyebabkan kemacetan lalu lintas.

b. Kemudahan pencapaian pengguna

c. Arah pergerakan lalu lintas

d. Tingkat keamanan akses

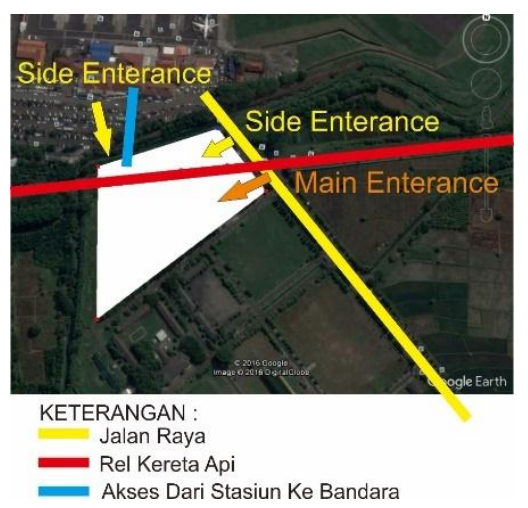

Proses Analisis

Gambar 2. Pencapaian

a. Main Entrance :

- Mudah ditemukan dan diakses dari jalan utama

- Menghadap langsung ke arah jalan untuk kemudahan akses pengguna 
- Keamanan akses

b. Side Entrance :

- Tidak terjadi cross dengan main entrance

- Menunjang fungsi main entrance

- Mendukung fungsi kegiatan bagi pengelola dan servis

Orientasi

1. Utara : Bandar Udara Ahmad Yani

2. Selatan : Sekolah Penerbangan TNI

3. Timur : Jalan Bandara Ahmad Yani

4. Barat : Jalan Jembawan Raya

\section{Pencahayaan}

Pencahayaan adalah faktor paling penting saat berada di stasiun bandara. Karena tanpa pencahayaan yang cukup, maka pengunjung atau penumpang akan kesulitan untuk melihat. Pencahayaan diusahakan menggunakan pencahayaan alami di siang hari agar lebih hemat energi. Pencahayaan alami didapat dari sinar matahari, yang tentunya sangat mengandalkan bukaan seperti pintu, jendela dan bouven light. Semakin besar bukaan maka semakin banyak pula cahaya matahari yang masuk kedalam bangunan.

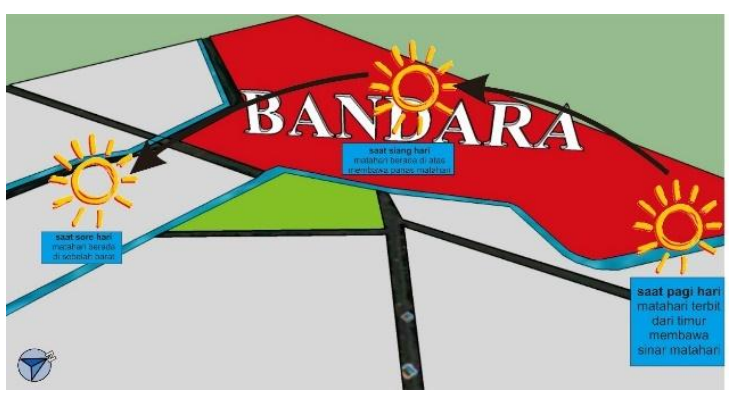

Gambar 3. Analisis Pencahayaan

Kebisingan

Sumber kebisingan pada tapak stasiun bandara adalah berada di bandara Ahmad Yani. Karena suara dari mesin pesawat terbang saat akan mendarat maupun akan terbang sangat keras sekali, sehingga sangat bising pada saat tersebut. Namun apabila tidak ada pesawat yang mendarat ataupun terbang, suasana pada tapak tidaklah bising sama sekali. Hanya pada bagian timur tapak sedikit ramai karena cukup banyak mobil, motor dan bus trans Semarang berlalu lalang.

\section{Arah Angin}

Ada dua angin yang melintasi Kota Semarang, yaitu angin muson barat dan angin muson timur. Angin muson barat terjadi pada bulan Oktober - Februari. Sedangkan angin muson timur terjadi pad abulan januari - september. Karena angin muson timur berhembus dari tenggara, maka perlu diberi beberapa vegetasi berupa pohon yang cukup tinggi sebagai penahan angin agar tidak langsung berhembus pada bangunan. Bangunan juga mengahadap kearah selatan agar angin juga dapat masuk namun tidak terlalu kencang, sehingga cukup membuat suasana didalam hall stasiun menjadi sejuk.

Sedangkankan pada bulan oktober - februari terjadi angin muson barat yang berhembus dari barat laut, angin dapat langsung masuk melalui celah antara 2 massa bangunan, yaitu bagian peron. Dengan masuknya angin kedalam peron, sehingga cukup memberi suasana sejuk pada peron stasiun. Maka hal tersebut dapat mencegah penggunaan $\mathrm{AC}$ dan kipas angin pada peron stasiun.

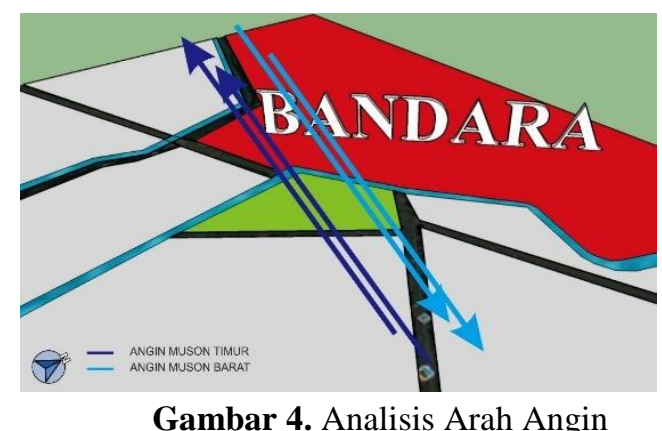

\section{Program Ruang}

Tujuan : Mengetahui ruangan-ruangan apa saja yang dibutuhkan oleh pengguna untuk melakukan kegiatanya di stasiun.

Dasar pertimbangan : Penentuan ruangan mengacu pada buku pedoman standarisasi stasiun tahun 2012, kegiatan dan pelaku kegiatanya.

Pelaku Kegiatan : Penumpang, Pengantar, Penjemput, Pedagang, Pengelola, Petugas dan Staff 
Tabel 1. Kebutuhan Ruang

\begin{tabular}{|c|c|c|}
\hline $\begin{array}{c}\text { Kebutuhan } \\
\text { ruang }\end{array}$ & $\begin{array}{c}\text { Pelaku } \\
\text { kegiatan }\end{array}$ & Kegiatan \\
\hline Hall / lobby & $\begin{array}{l}\text { Semua } \\
\text { Orang }\end{array}$ & $\begin{array}{l}\text { Area sirkulasi } \\
\text { bagi semua } \\
\text { orang }\end{array}$ \\
\hline loket & $\begin{array}{l}\text { Penumpa } \\
\text { ng }\end{array}$ & $\begin{array}{l}\text { Membeli tiket } \\
\text { kereta api }\end{array}$ \\
\hline $\begin{array}{l}\text { Electronic } \\
\text { Gate }\end{array}$ & $\begin{array}{l}\text { Penumpa } \\
\text { ng dan } \\
\text { petugas }\end{array}$ & $\begin{array}{l}\text { Pengecekan } \\
\text { tiket }\end{array}$ \\
\hline Ruang tunggu & $\begin{array}{l}\text { Penumpa } \\
\text { ng }\end{array}$ & $\begin{array}{l}\text { Menunggu } \\
\text { kereta datang }\end{array}$ \\
\hline $\begin{array}{l}\text { Ruang tunggu } \\
\text { VIP }\end{array}$ & $\begin{array}{l}\text { penumpa } \\
\text { ng }\end{array}$ & $\begin{array}{l}\text { Menunggu } \\
\text { kereta datang }\end{array}$ \\
\hline $\begin{array}{l}\text { Ruang } \\
\text { Tunggu } \\
\text { Eksklusif }\end{array}$ & $\begin{array}{l}\text { Penumpa } \\
\text { ng }\end{array}$ & $\begin{array}{l}\text { Menunggu } \\
\text { Kereta Datang }\end{array}$ \\
\hline $\begin{array}{l}\text { Ruang } \\
\text { menyusui }\end{array}$ & $\begin{array}{l}\text { penumpa } \\
\text { ng }\end{array}$ & Menyusui bayi \\
\hline Peron & $\begin{array}{l}\text { Penumpa } \\
\text { ng, } \\
\text { petugas }\end{array}$ & $\begin{array}{l}\text { Naik turunnya } \\
\text { penumpang } \\
\text { dari / ke kereta } \\
\text { api }\end{array}$ \\
\hline $\mathrm{KM} / \mathrm{WC}$ & $\begin{array}{l}\text { Penumpa } \\
\text { ng }\end{array}$ & $\begin{array}{l}\text { Buang Air } \\
\text { Kecil/Besar }\end{array}$ \\
\hline Parkir & $\begin{array}{l}\text { Semua } \\
\text { Orang }\end{array}$ & $\begin{array}{l}\text { Memarkirkan } \\
\text { kendaraanya }\end{array}$ \\
\hline Charging area & $\begin{array}{l}\text { penumpa } \\
\text { ng }\end{array}$ & $\begin{array}{l}\text { Mengisi } \\
\text { baterai HP }\end{array}$ \\
\hline ATM Center & $\begin{array}{l}\text { Semua } \\
\text { Orang }\end{array}$ & $\begin{array}{l}\text { Mengambil } \\
\text { Uang }\end{array}$ \\
\hline Mini Market & $\begin{array}{l}\text { Semua } \\
\text { Orang }\end{array}$ & Berbelanja \\
\hline Toko & $\begin{array}{l}\text { Semua } \\
\text { Orang }\end{array}$ & Berbelanja \\
\hline R. Transisi & $\begin{array}{l}\text { Semua } \\
\text { Orang }\end{array}$ & $\begin{array}{l}\text { Menuju } \\
\text { Bandara }\end{array}$ \\
\hline $\begin{array}{l}\text { Cafe / } \\
\text { Restaurant }\end{array}$ & $\begin{array}{l}\text { Semua } \\
\text { Orang }\end{array}$ & Makan/Minum \\
\hline $\begin{array}{l}\text { R. Kepala } \\
\text { Stasiun }\end{array}$ & $\begin{array}{l}\text { Kepala } \\
\text { Stasiun }\end{array}$ & Bekerja \\
\hline $\begin{array}{l}\text { R. wakil } \\
\text { Kepala } \\
\text { Stasiun } \\
\end{array}$ & $\begin{array}{l}\text { Wakil } \\
\text { Kepala } \\
\text { Stasiun } \\
\end{array}$ & Bekerja \\
\hline $\begin{array}{l}\text { R. Kepala } \\
\text { Oprasional }\end{array}$ & $\begin{array}{l}\text { Kepala } \\
\text { Oprasion } \\
\text { al } \\
\end{array}$ & $\begin{array}{l}\text { Mengelola } \\
\text { Oprasional } \\
\text { Stasiun } \\
\end{array}$ \\
\hline $\begin{array}{l}\text { R. Bidang } \\
\text { Administrasi }\end{array}$ & $\begin{array}{l}\text { Staff } \\
\text { Administ } \\
\text { rasi }\end{array}$ & $\begin{array}{l}\text { Mengelola } \\
\text { administrasi }\end{array}$ \\
\hline R. PPKA & $\begin{array}{l}\text { Kepala } \\
\text { dan Staff } \\
\text { PPKA }\end{array}$ & $\begin{array}{l}\text { Memantau } \\
\text { kedatangan } \\
\text { KA }\end{array}$ \\
\hline
\end{tabular}

\begin{tabular}{|c|c|c|}
\hline R. Peralatan & Teknisi & $\begin{array}{l}\text { Menyimpan } \\
\text { peralatan } \\
\text { stasiun }\end{array}$ \\
\hline R. Keamanan & $\begin{array}{l}\text { petugas } \\
\text { keamana } \\
\mathrm{n}\end{array}$ & $\begin{array}{l}\text { Menjaga } \\
\text { keamanan } \\
\text { stasiun }\end{array}$ \\
\hline $\begin{array}{l}\text { R. Petugas } \\
\text { Kebersihan }\end{array}$ & $\begin{array}{l}\text { Petugas } \\
\text { Kebersiha } \\
\mathrm{n} \\
\end{array}$ & $\begin{array}{l}\text { Menjaga } \\
\text { Kebersihan } \\
\text { Staisun }\end{array}$ \\
\hline R. Rapat & $\begin{array}{l}\text { Pengelola } \\
\text { dan } \\
\text { Tamu } \\
\end{array}$ & $\begin{array}{l}\text { Rapat dan } \\
\text { berdiskusi }\end{array}$ \\
\hline R. RAP & Petugas & $\begin{array}{l}\text { Memberikan } \\
\text { layanan } \\
\text { informasi }\end{array}$ \\
\hline $\begin{array}{l}\text { R. UPT Kru } \\
\text { KA }\end{array}$ & $\begin{array}{l}\text { Kepala } \\
\text { dan Staff }\end{array}$ & Bekerja \\
\hline R. Serbaguna & Pengelola & $\begin{array}{l}\text { Mengadakan } \\
\text { Acara }\end{array}$ \\
\hline $\begin{array}{l}\text { R. Bidang } \\
\text { Komersial }\end{array}$ & $\begin{array}{l}\text { Kepala } \\
\text { dan Staff }\end{array}$ & $\begin{array}{l}\text { Mengelola } \\
\text { komersial } \\
\text { yang ada di } \\
\text { stasiun }\end{array}$ \\
\hline $\begin{array}{l}\text { R. Penjaga } \\
\text { parkir }\end{array}$ & $\begin{array}{l}\text { Petugas } \\
\text { Parkir }\end{array}$ & $\begin{array}{l}\text { Mengatur } \\
\text { Parkir }\end{array}$ \\
\hline $\begin{array}{l}\text { Pos } \\
\text { keamanan }\end{array}$ & $\begin{array}{l}\text { Petugas } \\
\text { keamana } \\
\mathrm{n}\end{array}$ & $\begin{array}{l}\text { Menjaga } \\
\text { keamanan } \\
\text { stasiun }\end{array}$ \\
\hline Mushola & $\begin{array}{l}\text { Semua } \\
\text { orang }\end{array}$ & Beribadah \\
\hline R. Medis & $\begin{array}{l}\text { Semua } \\
\text { orang }\end{array}$ & Berobat \\
\hline $\begin{array}{l}\text { R. Cleaning } \\
\text { Service }\end{array}$ & $\begin{array}{l}\text { Office } \\
\text { Boy }\end{array}$ & $\begin{array}{l}\text { Membersihkan } \\
\text { area stasiun }\end{array}$ \\
\hline $\begin{array}{l}\text { R. Penjaga } \\
\text { parkir }\end{array}$ & $\begin{array}{l}\text { Petugas } \\
\text { Parkir }\end{array}$ & $\begin{array}{l}\text { Mengatur } \\
\text { parkir }\end{array}$ \\
\hline Pantry & Petugas & $\begin{array}{l}\text { Membuat } \\
\text { makanan atau } \\
\text { minuman }\end{array}$ \\
\hline R. informasi & Petugas & $\begin{array}{l}\text { Memberi } \\
\text { informasi }\end{array}$ \\
\hline $\begin{array}{l}\text { Costumer } \\
\text { Service }\end{array}$ & Petugas & $\begin{array}{l}\text { Melayani dan } \\
\text { menjawab } \\
\text { pertanyaan } \\
\text { penumpang }\end{array}$ \\
\hline Gudang & Petugas & $\begin{array}{l}\text { Menyimpan } \\
\text { Barang }\end{array}$ \\
\hline R. Genset & Petugas & $\begin{array}{l}\text { Menyimpan } \\
\text { Genset }\end{array}$ \\
\hline R. AHU & Petugas & Mengontrol \\
\hline R. Panel & Petugas & Mengontrol \\
\hline Ground Tank & Petugas & Mengontrol \\
\hline Roof Tank & Petugas & Mengontrol \\
\hline R. Pompa & Petugas & Mengontrol \\
\hline R. CCTV & Petugas & Memantau \\
\hline R. Sinyal & Petugas & Mengontrol \\
\hline
\end{tabular}


Pola Hubungan Ruang

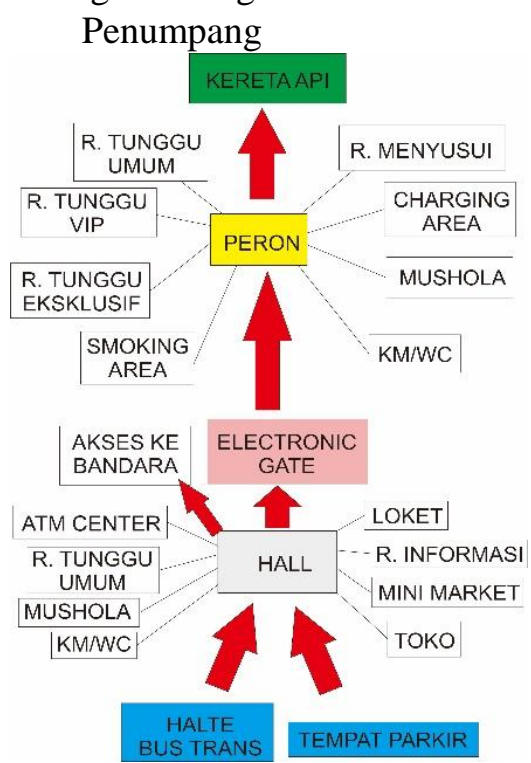

Gambar 5. Pola Hubungan Ruang Penumpang

Petugas dan Pengelola

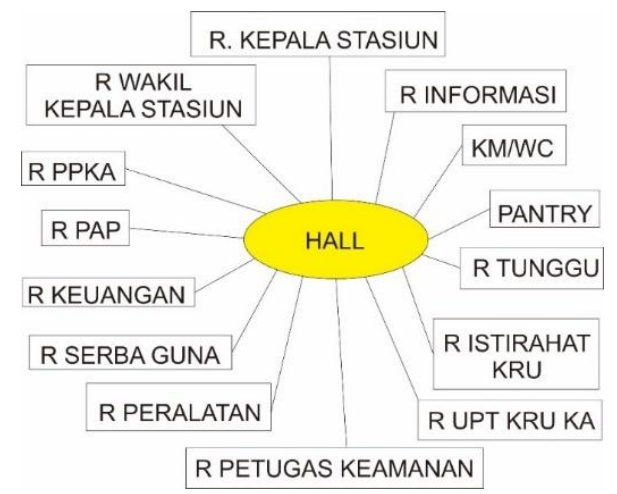

Gambar 6. Pola Hubungan Ruang Petugas dan Pengelola

Besarang Ruang

Tabel 2. Besaran Kelompok Ruang

\begin{tabular}{|c|c|}
\hline Kelompok ruang & $\begin{array}{c}\text { Luas total } \\
\left(\mathbf{m}^{\mathbf{2}}\right)\end{array}$ \\
\hline Area Stasiun & 9.821 \\
\hline Area Parkir & 4.260 \\
\hline Ruang Terbuka Hijau (30\%) & 6.863 \\
\hline Area Rel Kereta Api & 1.930 \\
\hline TOTAL & $\mathbf{2 2 . 8 7 4}$ \\
\hline
\end{tabular}

Area stasiun yang akan di desain adalah 9.821 $\mathrm{m} 2$. Berdasarkan pada standart minimum ruangan yang tertera pada "Pedoman Standardisasi Stasiun" maka ruangan-ruangan yang ada dalam stasiun beserta luasnya adalah sebagai berikut:
Tabel 3. Besaran Ruang

\begin{tabular}{|c|c|c|}
\hline No. & RUANG & LUAS ( $\left.\mathbf{m}^{2}\right)$ \\
\hline 1 & R. kepala stasiun & 60 \\
\hline 2 & R. wakil kepala stasiun & 60 \\
\hline 3 & R. PPKA & 50 \\
\hline 4 & R. PAP & 50 \\
\hline 5 & R. Keuangan & 50 \\
\hline 6 & R. Serba guna & 200 \\
\hline 7 & R. Peralatan & 50 \\
\hline 8 & R. UPT Kru KA & 50 \\
\hline 9 & R. Istirahat Kru & 100 \\
\hline 10 & R. Petugas Keamanan & 50 \\
\hline 11 & Hall & 500 \\
\hline 12 & Loket & 50 \\
\hline 13 & R. Pelayanan Informasi & 50 \\
\hline 14 & R. Tunggu VIP & 200 \\
\hline 15 & R. Tunggu Eksklusif & 150 \\
\hline 16 & R. Tunggu Umum & 1000 \\
\hline 17 & R. Layanan Kesehatan & 50 \\
\hline 18 & Toilet & 120 \\
\hline 19 & Mushola & 100 \\
\hline 20 & R. Ibu Menyusui & 30 \\
\hline 21 & ATM Center & 30 \\
\hline 22 & Mini Market & 100 \\
\hline 23 & Toko Oleh-Oleh & 500 \\
\hline 24 & $\begin{array}{l}\text { R. Transisi stasiun - } \\
\text { bandara }\end{array}$ & 2000 \\
\hline 25 & Cafe / Restaurant & 500 \\
\hline 26 & Gundang & 50 \\
\hline 27 & Peron & 3671 \\
\hline \multicolumn{2}{|r|}{ TOTAL } & 9821 \\
\hline
\end{tabular}

Orientasi Bangunan

Berdasarkan analisis view dan orientasi, maka orientasi bangunan stasiun bandara Ahmad Yani ini adalah menghadap ke selatan. Bangunan menghadap ke selatan karena lahan parkir akan ditempatkan di bagian selatan tapak. Sehingga penumpang akan dengan mudah mengakses loket tiket.

Kemudian massa kedua berada di sebelah utara rel. Fungsi dari massa tersebut adalah sebagai ruang transisi bagi penumpang yang ingin berganti moda transportasi pesawat. Maka stasiun menyediakan fasilitas berupa akses penghubung antara stasiun dan bandara. Maka massa kedua ini menghadap keutara. Disamping menjadi massa transisi, massa ini digunakan sebagai pintu masuk bagi penumpang yang ingin melanjutkan perjalanan dari pesawat terbang menjadi kereta api. 


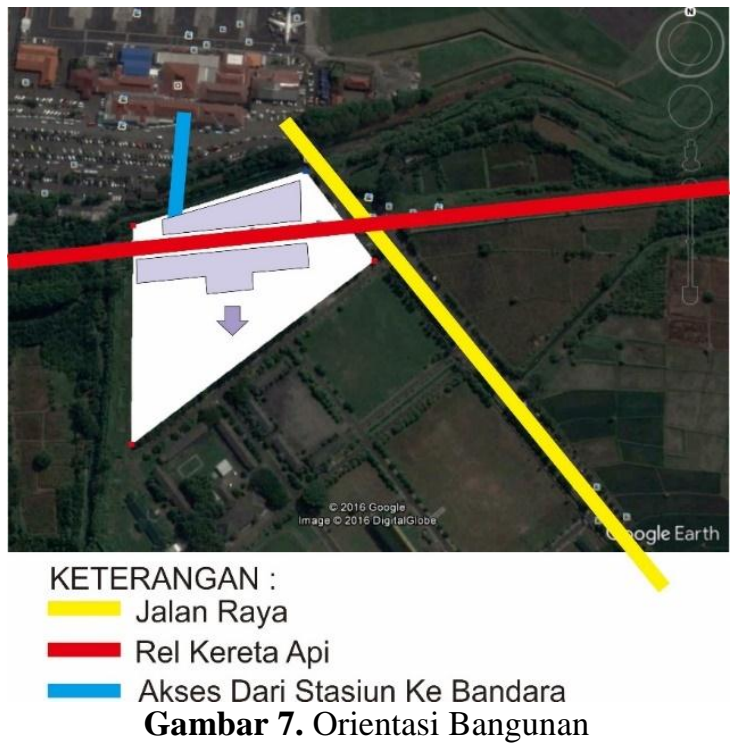

Sirkulasi

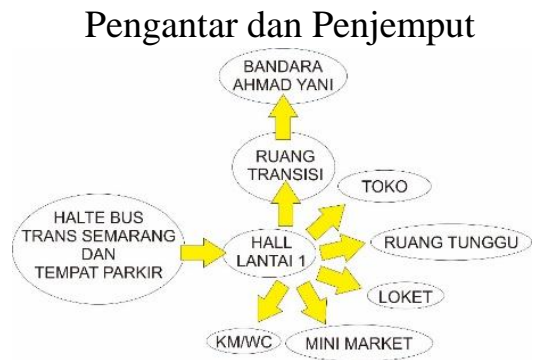

Gambar 8. Sirukulasi Pengantar dan Penjemput

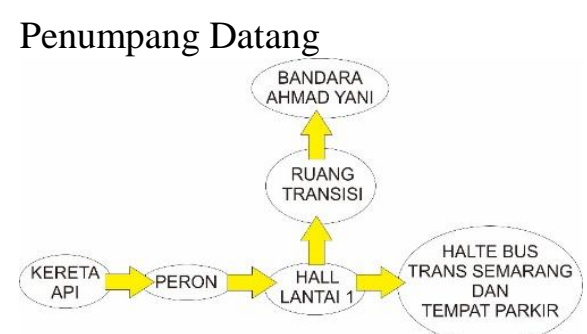

Gambar 9. Sirukulasi Penumpang Datang

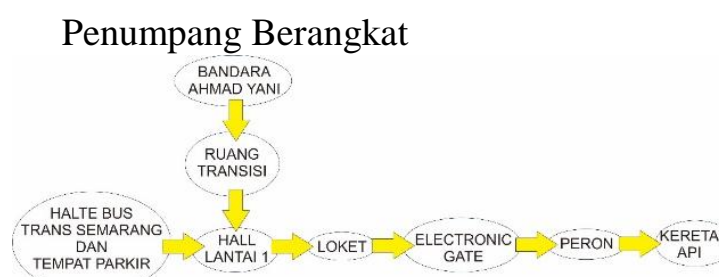

Gambar 10. Sirukulasi Penumpang Berangkat

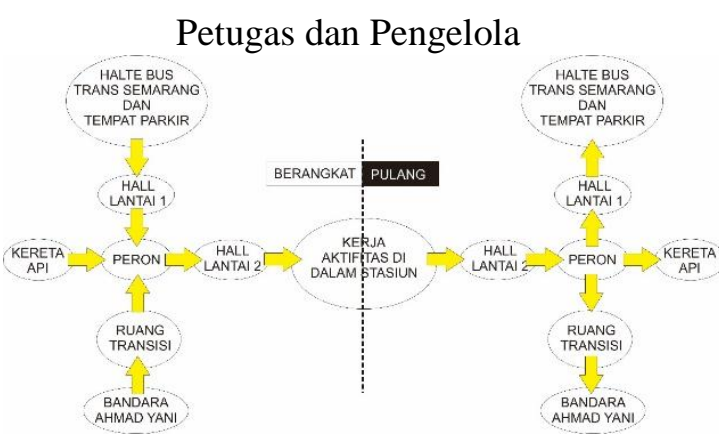

Gambar 11. Sirukulasi Petugas dan Pengelola

Gubahan Massa

Tujuan : Bentuk bangunan disesuaikan dengan bentuk-bentuk stasiun yang sudah ada dan menyelaraskan dengan bangunan bandara.

Dasar Pertimbangan :

a. Agar tidak terjadi perbedaan yang signifikan antara bentuk bangunan bandara dengan bentuk bangunan stasiun.

b. Bentuk yang unik dan menonjol agar masyarakat tau bahwa bangunan tersebut adalah bangunan stasiun.

Analisis :

Bangunan stasiun umumnya sama, yakni berupa persegi panjang. Karena bangunan stasiun harus dapat mewadahi penumpang yang akan naik menuju gerbong yang mereka tuju. Sehingga stasiun berbenduk persegi panjang agar dapat memudahkan penumpangnya. Maka dari itu bentuk bangunan stasiun bandara tersebut berbentuk persegi panjang yang mana terdapat 2 massa bangunan. Massa utama berada di sisi selatan memfasilitasi penumpang yang akan naik kereta di jalur 1. Sedangkan massa ke dua berada di sisi utara yang dapat menfasilitasi penumpang yang akan naik kereta di jalur 4 .

Sedangkan untuk bentuk atapnya menggunakan atap limasan. Atap limasan pada massa utama dan massa ke 2 adalah berupa kuda-kuda baja dengan penutup genteng. Sedangkan atap limasan pada penutup peron adalah berupa baja H-Beam dengan penutup kaca.

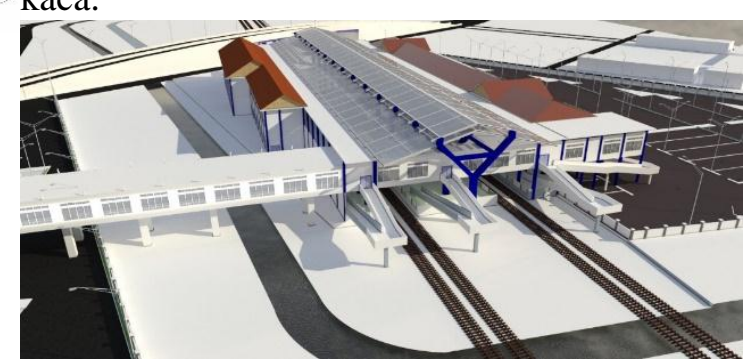

Gambar 12. Bentuk Bangunan 
Tampilan Bangunan

1. Tujuan : memperlihatkan fasad bangunan secara keseluruhan

2. Dasar pertimbangan : memadukan keselarasan dan keserasian antara bangunan stasiun dengan bangunan bandara Ahmad Yani Semarang.

3. Analisis :

Stasiun kereta api pada bandar udara ahmad yani ini berbentuk persegi panjang dengan atap limasan seperti yang sudah dijelaskan pada poin gubahan masa. Untuk mendukung keserasian bangunan ini maka teknik pewarnaan pada bangunan juga sangat berpengaruh seperti penambahan warna biru pada kolom dan warna putih pada kolom sehingga menimbulkan kesan bersih. Sedangkan bentuk atap limasan pada penutup peron yang menggunakan baja dengan penutup kaca sehingga terlihat bahwa bangunan ini lebih futuristik namun tidak kontras dengan bangunan bandara ahmad yani yang masih menggunakan atap limasan dengan penutup genteng.

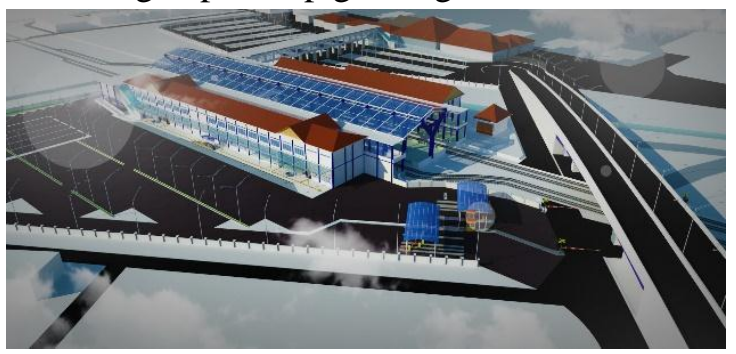

Gambar 13. Tampilan Bangunan

\section{KESIMPULAN}

Bangunan staisun kereta api pada bandara ahmad yani semarang adalah sebuah fasilitas publik bagi masyarakat untuk dapat mengakses bandara ahmad yani. Sehingga dengan adanya stasiun kereta api pada bandara ahmad yani semarang ini diharapkan dapat mengurangi kemacetan yang sering terjadi di kota semarang, khususnya akses utama menuju kearah bandara.

Stasiun kereta api ini berjenis stasiun sedang atau bisa disebut dengan stasiun kelas 2 yang mana kereta api berjenis ekonomi dan bisnis dapat berhenti di stasiun bandara ini. Karena kereta api berjenis ekonomi lebih sering beroprasi jarak dekat. Sehingga hal tersebut memudahkan masyarakat yang bertempat tinggal di luar semarang seperti kendal, batang, pekalongan, jepara, kudus, dll yang ingin bepergian jauh menggunakan pesawat terbang.

Bangunan stasiun ini terdiri dari dua massa bangunan. Kedua massa bangunan mengapit rel kereta api pada sisi utara dan sisi selatan rel kereta api. Untuk massa utamanya yaitu berada pada sisi selatan rel kereta api, karena lahan yang lebih besar sehingga dapat berinteraksi langsung dengan lahan parkir dan memudahkan pengunjung untuk mengaksesnya. Sedangkan untuk massa kedua berada pada sisi utara rel kereta api

Massa bangunan pertama adalah massa utama dari stasiun bandara ini. Fasilitas yang disediakan pun lengkap untuk semua pengguna. Selanjutnya untuk massa kedua adalah sebuah bangunan yang berada di sisi utara rel kereta api. Tidak berbeda jauh dengan massa utama yang ada di sisi selatan rek kereta api. Massa kedua ini juga memiliki fasilitas penumpang yang sama dengan massa utama bangunan stasiun bandara ini. Namun bedanya terletak pada lantai dua nya. Lantai dua pada massa kedua stasiun bandara ini adalah sebagai area pengelola stasiun, seperti ruang keamanan, ruang CCTV, pantry, ruang makan, dan ruang istirahat bagi kru kereta api. Sedangkan pada lantai 2 massa utama bangunan adalah berupa area perkantoran bagi pengelola stasiun

Karena bangunan ini adalah stasiun bandara, maka stasiun ini harus terintegrasi dengan bandara Ahmad Yani Semarang. Dibutuhkan suatu penghubung antara stasiun dengan bandara. Yaitu sebuah jembatan penyebrangan. Jarak antara stasiun dengan bandara adalah sekitar $100 \mathrm{~m}$. Maka pada jembatan penghubung ini juga disediakan travelator. Yaitu sebuah escalator namun horizontal. Sehingga penumpang yang lelah setelah perjalanan jauh, dapat menggunakan travelator untuk menuju ke stasiun/bandara untuk berganti moda transportasi.

Untuk mengakses bangunan stasiun ini dapat menggunakan kendaraan pribadi seperti mobil dan motor, namun juga dapat menggunakan kendaraan umum seperti bus trans semarang. Karena pada bagian depan bangunan telah disediakan halte bus yang mana dapat mempermudah masyarakat yang ingin 
melanjutkan perjalananya menggunakan bus trans semarang.

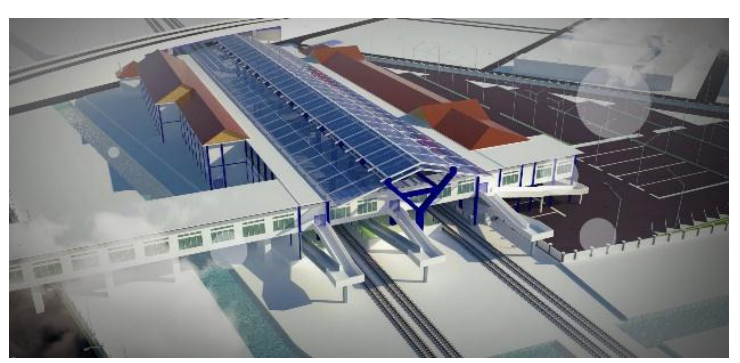

Gambar 14. Bentuk Bangunan Stasiun

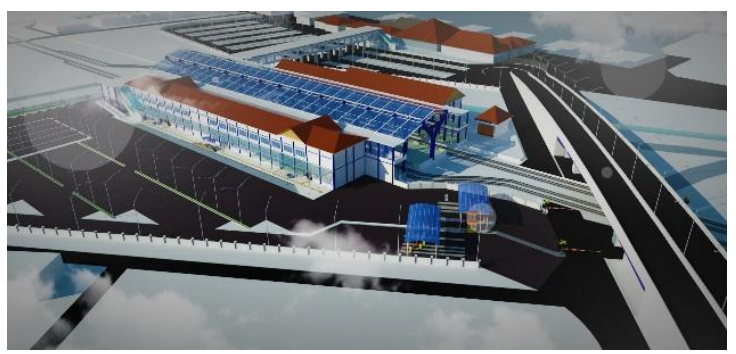

Gambar 15. Bentuk Bangunan Stasiun

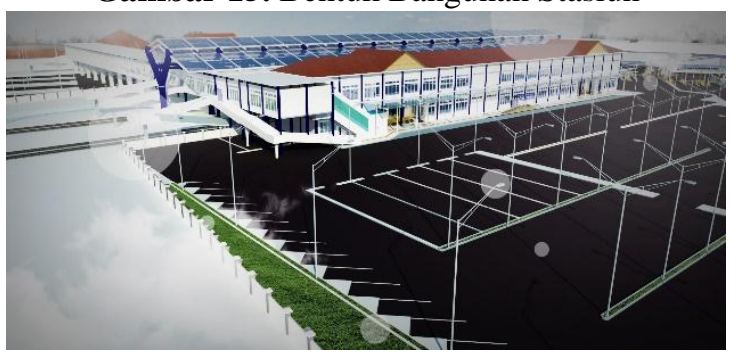

Gambar 16. Bentuk Bangunan Stasiun

\section{REFERENSI}

Azis, M.A., 2009. Analisis Faktorfaktor Yang Mempengaruhi Konsumsi Masyarakat Di Provinsi Jawa Tengah Tahun 2003-2007 (Studi Kasus Kota Semarang, Solo, Purwokerto dan Tegal). Universitas Sebelas Maret.

Purwanto, E., 2008. Kajian Arsitektural Stasiun Nis. J. Ilm. Peranc. Kota Dan Permukim. 7, 98-105.

Sewarchitect, 2014. Perencanaan Sarana Prasarana Permukiman Kelurahan Banyumanik RW 4, Semarang Tahun 2014-2024. Dunia Arsitek SEW.

Peraturan Menteri Perhubungan Nomor 35 tahun 2003 tentang penyelenggaraan angkutan orang di jalan dengan kendaraan umum.
Peraturan Mentri Perhubungan Nomor 43 Tahun 2011 Tentang Rencana Induk Kereta Api Nasional.

Peraturan Mentri Perhubungan Nomor 47 Tahun 2017 Tentang Pelayanan minimum untuk angkutan orang dengan kereta api. 